\title{
Electrochemical behaviour of denatured haemoglobin at the liquid|liquid interface
}

\author{
Grégoire Herzog, Patrycja Eichelmann-Daly, Damien W. M. Arrigan*, 1
}

Tyndall National Institute, Lee Maltings, University College Cork, Cork, Ireland

\begin{abstract}
* Corresponding author: email: d.arrigan@ curtin.edu.au; fax: +61-8-9266-4699; phone: +618-9266-9735.
\end{abstract}

${ }^{1}$ Present Address: Nanochemistry Research Institute, Department of Chemistry, Curtin University of Technology, GPO Box U1987, Perth, WA 6845, Australia. Journal: Electrochemistry Communications

\begin{abstract}
:
We report here the influence of chemical denaturation of haemoglobin on its electrochemical behaviour at the polarised liquid|liquid interface. Denaturation with urea resulted in a modification of the haemoglobin electrochemical behaviour, with the disappearance of the forward transfer peak and a decrease of the reverse peak current. Although the reverse peak current increased linearly with the concentration of denatured haemoglobin in the aqueous phase, the slope of the current-concentration plot was three times lower than that for native haemoglobin over the $0.1-1 \mu \mathrm{M}$ concentration range. These results indicate the sensitivity of electrochemistry at liquid|liquid interfaces to protein tertiary structure.
\end{abstract}

Keywords: Protein, denaturation, haemoglobin, voltammetry, liquid | liquid interface.

\section{Introduction}

Proteins are the molecular machines of life and tools for their detection enable both the study of biological processes and the diagnosis of disease. Electrochemical methods provide important analytical tools for protein detection [1]. Amongst these, electrochemistry at polarised liquid|liquid interfaces has been used for the investigation of non-redox electrochemistry [2,3] and electroanalytical determination [4] of a range of ions. Recently, a variety of large polycationic molecules have been studied at the liquid|liquid interface, 
including dendrimers [5], peptides [6] and proteins [7-20]. We have recently investigated the electrochemical behaviour of haemoglobin [15-17], insulin [18] and lysozyme [19] at the liquid | liquid interface. In agreement with previous studies [7-10, 14, 20], protein adsorption occurred on the aqueous side of the aqueous|organic interface and the charge transfer process was attributed to transfer of organic-phase electrolyte anion into the aqueous phase where it formed a complex with the adsorbed polycationic protein [14-16, 18, 19]. The availability of hydrophobic pockets within the proteins' structures facilitated complexation with the hydrophobic anions of the organic phase. It was also surmised that protein conformational changes occurred at the interface, especially following the interactions with the hydrophobic anion of the organic phase $[15,17]$.

As the natural function of proteins is determined by their tertiary structure, the investigation of the modification of this structure is important. Protein denaturation (or unfolding) has been investigated by a range of techniques, such as fluorescence, Raman and infra-red spectroscopies and NMR and mass spectrometry [21]. Protein unfolding has also been investigated by electrochemical means for cytochrome $c$ [22-26], bovine serum albumin [27] and haemoglobin [28].

We report here the influence of the chemical denaturation of haemoglobin on its cyclic voltammetric behaviour at the liquid|liquid interface, as part of our on-going studies of protein electrochemical behaviour and detection. In the present study, haemoglobin was denatured using either urea $(9.5 \mathrm{M})$ or guanidine hydrochloride $(7 \mathrm{M})$. The aim of this study was to investigate whether protein unfolding alters the electrochemical behaviour at the liquid|liquid interface. If denaturation destroys the hydrophobic pockets available within the tertiary structure of haemoglobin, then there should be less anion transfer facilitated by the protein. The results presented show that the denatured protein is less electroactive at the liquid|liquid interface and that analytical sensitivity is decreased relative to that of the native protein.

\section{Experimental details}

All reagents were purchased from Sigma-Aldrich Ireland Ltd and were used as received. The organic phase electrolyte salt was bis-(triphenylphosphoranylidene) ammonium tetrakis(4chlorophenyl)-borate $\left(\left(\mathrm{BTPPA}^{+}\right)\left(\mathrm{TPBCl}^{-}\right)\right)$, prepared by metathesis of bis(triphenylphosphoranylidene) ammonium chloride with potassium tetrakis(4-chlorophenyl)- 
borate. The organic solvent was 1,2-dichloroethane (1,2-DCE). The composition of the electrochemical cell is shown in Scheme 1.

Haemoglobin was denatured overnight at room temperature using either $9.5 \mathrm{M}$ urea in $0.15 \mathrm{M}$ $\mathrm{KCl}+0.15 \mathrm{M} \mathrm{HCl}$ or $7 \mathrm{M}$ guanidine $\mathrm{HCl}$. Purified water with a resistivity of $18 \mathrm{M} \Omega \mathrm{cm}$, from an Elgastat system (Elga, UK), was used in the preparation of all aqueous solutions.

All voltammetric experiments were performed with a PGSTAT302N potentiostat (Ecochemie B.V. The Netherlands). A four-electrode electrochemical cell with a pair of $\mathrm{Ag} \mid \mathrm{AgCl}$ reference electrodes (one in each phase) and a pair of Pt mesh counter electrodes (one in each phase) was used. The interfacial geometric area was $1.16 \mathrm{~cm}^{2}$ and was flat in appearance. All potentials are reported relative to the experimentally used reference electrodes. The potential range was scanned from $+0.1 \mathrm{~V}$ towards more positive potentials. In all experiments, a positive cell current indicated the transfer of a cation from the aqueous phase to the organic phase, or of an anion from the organic to the aqueous phase. A negative current indicated the transfer of an anion of the aqueous phase to the organic phase or of a cation of the organic phase to the aqueous phase. All experiments were done at ambient room temperature $\left(20 \pm 1^{\circ}\right.$ C).

\section{Results and Discussion.}

The electrochemical behaviour of haemoglobin (Figure 1) was investigated by cyclic voltammetry (CV) before and after denaturation with urea. The presence of native haemoglobin in the aqueous phase gave a pair of peaks $(+0.78 \mathrm{~V}$ on the forward scan and + $0.68 \mathrm{~V}$ on the reverse) in agreement with previous studies $[15,16]$. These peaks were attributed to the transfer of the anion of the electrolyte of the organic phase facilitated by the presence of haemoglobin on the aqueous side of the interface. The addition of denatured haemoglobin to a $10 \mathrm{mM} \mathrm{HCl}$ aqueous phase resulted in a very different $\mathrm{CV}$ (Figure 1). The forward peak was decreased to the extent that it was not discernible above the background current and the reverse peak was shifted to less positive potentials and was of lower intensity. The additional reverse peak observed at $+0.7 \mathrm{~V}$ was due to the change in the background electrolyte. Control experiments (not shown) demonstrated that this electrochemical protein signal was not due to the composition of the aqueous electrolyte solution. The presence of urea in the denaturation medium was necessary to observe a modification of the electrochemical signal for haemoglobin. Furthermore, the aqueous electrolytes were acidic 
( $\mathrm{pH} 1.4$ for $0.15 \mathrm{M} \mathrm{KCl}+0.15 \mathrm{M} \mathrm{HCl}$; $\mathrm{pH} 1.9$ for $10 \mathrm{mM} \mathrm{HCl}$ ) so that the haemoglobin was fully protonated and positively charged. This ensured that the changes in electrochemical behaviour were due to the modification of haemoglobin tertiary structure and not to the changes of aqueous electrolyte $\mathrm{pH}$. Previous studies of proteins at the liquid|liquid interface demonstrated that electrochemical detection occurs only when the protein is present in solution at a pH below its isoelectric point, so that it is positively charged $[15,18,19]$.

In $10 \mathrm{mM} \mathrm{HCl}$, haemoglobin may be partially unfolded. However, it has been reported that at $\mathrm{pH}<2.5$ haemoglobin retains a large amount of tertiary structure in which the highly hydrophobic tryptophan residues have little exposure to the surrounding solvent [29]. Chemical denaturants, such as urea and guanidine $\mathrm{HCl}$, destabilise the hydrophobic interactions, leading to its full unfolding [30]. Such destruction of hydrophobic pockets should, in principle, result in transfer of less hydrophobic anion across at the interface. Indeed, the charge under the reverse $\mathrm{CV}$ peak before denaturation was $467 \mu \mathrm{C}$, but this dropped to $63 \mu \mathrm{C}$ after protein unfolding, indicating that there was less interaction between the protein in the aqueous phase and the anion of the organic electrolyte phase after denaturation. These results suggest that hydrophobic interactions, as well as electrostatic interactions $[15,18,19]$, between proteins and anions of the organic electrolyte phase are important.

The peak intensity on the reverse scan increased with the concentration of the denatured protein in the aqueous phase (Figure 2). It can also be seen that the forward transfer peak current became more obvious with increasing concentration of denatured protein. A plot of the reverse peak current versus the concentration of denatured haemoglobin (Figure 2, inset) had a slope of $-32 \mu \mathrm{A} \mu \mathrm{M}^{-1}(\mathrm{~N}=10)$. This was three-times lower than that obtained for native haemoglobin $\left(-101 \mu \mathrm{A} \mu \mathrm{M}^{-1}, \mathrm{~N}=10\right)$, indicating the sensitivity of liquid|liquid interface electrochemistry to protein tertiary structure.

Further experiments using $7 \mathrm{M}$ guanidine $\mathrm{HCl}$ as the denaturation medium were carried out. Figure 3 shows that the addition of $7 \mathrm{M}$ guanidine $\mathrm{HCl}$ to the aqueous phase (so that $0.69 \mathrm{M}$ guanidine $\mathrm{HCl}$ was in solution) resulted in an increase of the background current, attributed to the high ionic strength. A broad peak was observed on the reverse scan, due to the background electrolyte. Upon addition of an aliquot of $100 \mu \mathrm{M}$ of haemoglobin denatured by 
guanidine $\mathrm{HCl}$ to the aqueous phase (providing concentrations of $1 \mu \mathrm{M}$ haemoglobin and 0.69 $\mathrm{M}$ guanidine $\mathrm{HCl}$ ), the reverse scan peak was broadened and shifted towards less positive potentials. The high background current masked the haemoglobin signal and it was not possible to assess the influence of guanidine $\mathrm{HCl}$ denaturation medium on the behaviour of haemoglobin. It was also seen that the organic phase turned white and cloudy after experiments, irrespective of whether haemoglobin was present or not. This suggests that guanidinium was transferred from the aqueous to the organic phase.

\section{Conclusions}

Denaturation of haemoglobin by urea caused a substantial decrease of the electrochemical detection signal at the liquid|liquid interface. This decreased electrochemical behaviour may be explained by the destruction of hydrophobic pockets within the protein upon denaturation by urea, which in turn decreased the extent of interaction between the cationic protein and the organic phase electrolyte anion. Despite a decreased electrochemical signal for denatured haemoglobin, the transfer peak current on the reverse CV scan increased linearly with the concentration of unfolded haemoglobin in the aqueous phase, although the sensitivity was three-times less than that for native haemoglobin. The results presented indicate the sensitivity of electrochemistry at liquid|liquid interfaces to protein tertiary structure and that denatured proteins are less electroactive at these interfaces.

\section{Acknowledgments}

This work was supported by Science Foundation Ireland (07/IN.1/B967 and 09/UR/I1526). 


\section{Figure and Scheme captions}

Figure 1: $\mathrm{CV}$ of $10 \mathrm{mM} \mathrm{HCl}$ (solid line), $0.2 \mu \mathrm{M}$ native haemoglobin (dotted line) and 0.2 $\mu \mathrm{M}$ haemoglobin denatured in $9.5 \mathrm{M}$ urea (concentration in aqueous phase was $0.19 \mu \mathrm{M}$ ) (dashed line).

Figure 2: $\mathrm{CV}$ of increasing concentrations of haemoglobin denatured in $9.5 \mathrm{M}$ urea added to a $10 \mathrm{mM} \mathrm{HCl}$ aqueous phase. Concentrations of denatured haemoglobin were $0,0.1,0.2,0.3$, $0.4,0.5,0.6,0.7,0.8,0.9$ and $1 \mu \mathrm{M}$. Inset: Calibration graphs for native (•) and denatured haemoglobin (ם).

Figure 3: $\mathrm{CV}$ of $10 \mathrm{mM} \mathrm{HCl}$ (solid line), $0.69 \mathrm{M}$ guanidine in $10 \mathrm{mM} \mathrm{HCl}$ (dotted line) and 1 $\mu \mathrm{M}$ haemoglobin + 0.69 M guanidine in $10 \mathrm{mM} \mathrm{HCl}$ (dashed line).

Scheme 1: Composition of the electrochemical cell employed. 
Figure 1

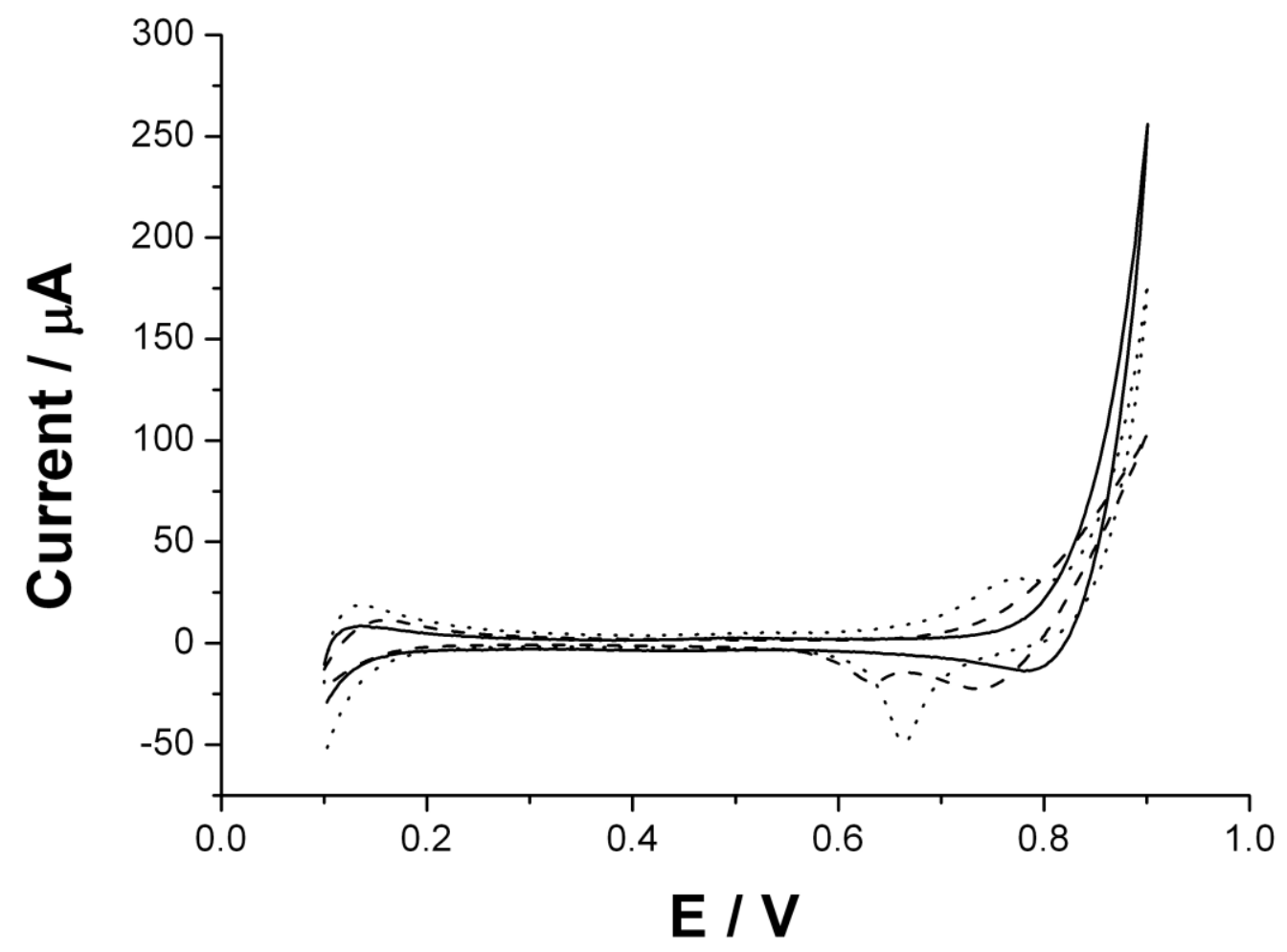


Figure 2

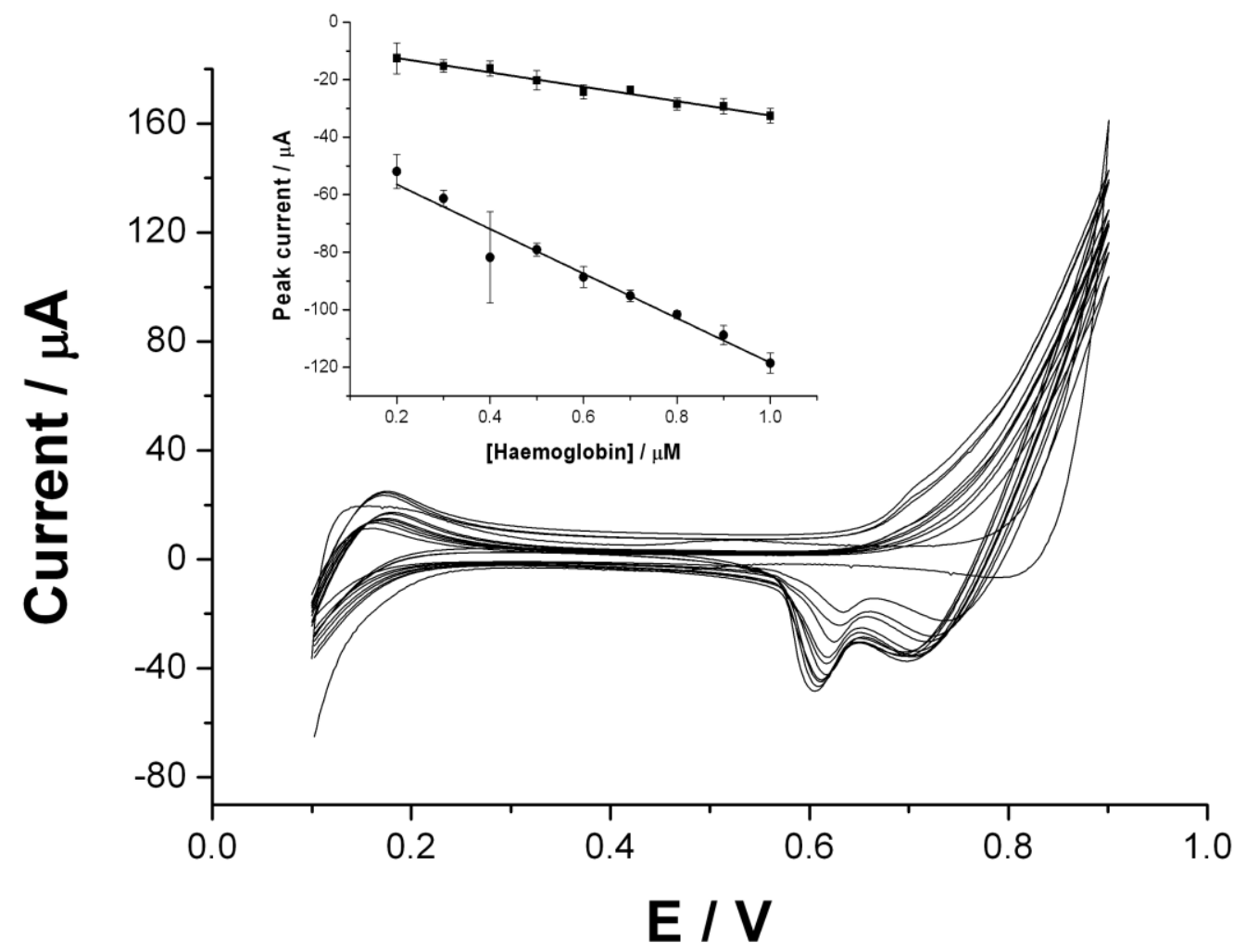


Figure 3

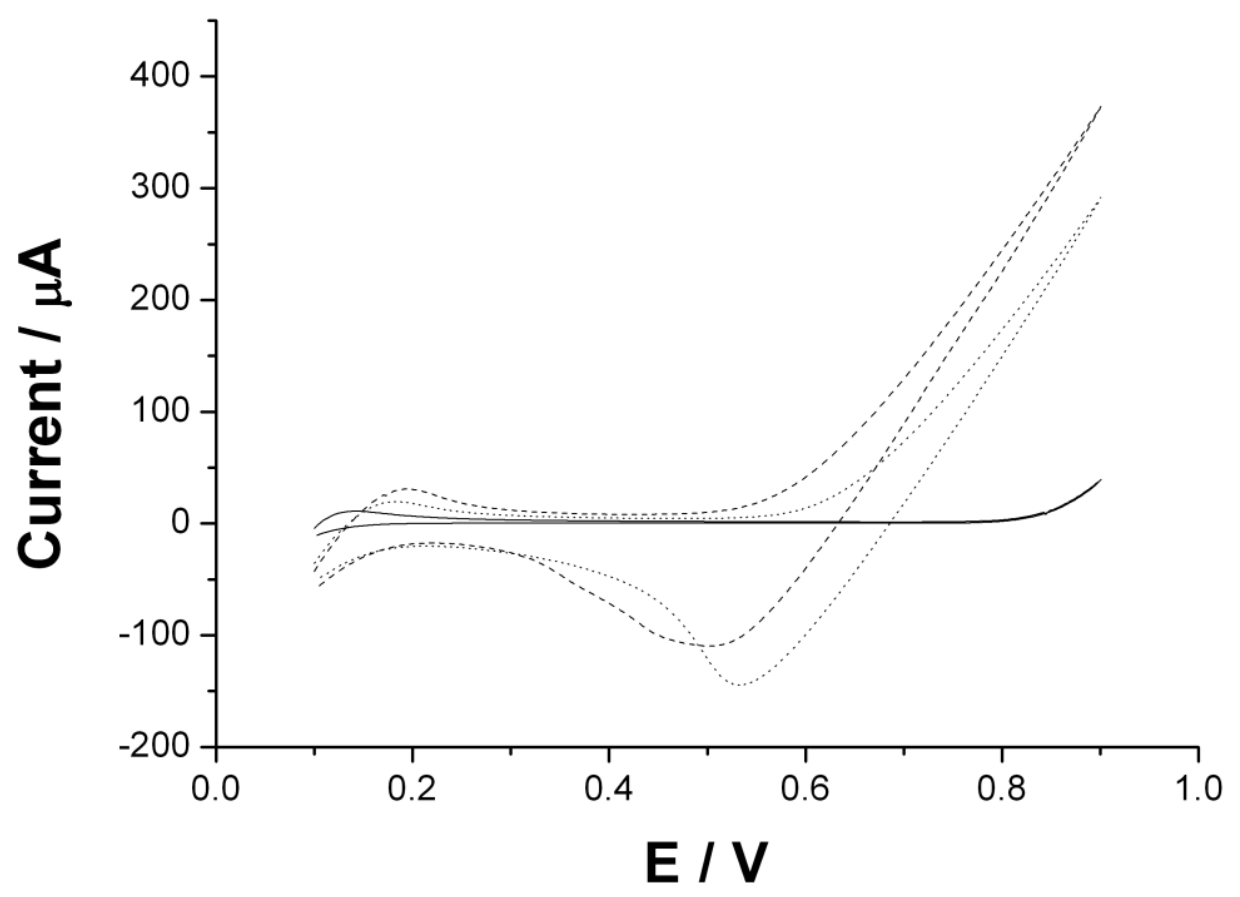


Scheme 1






\section{References}

[1] G. Herzog, D.W.M. Arrigan, Analyst, 132 (2007) 615.

[2] Z. Samec, Chemical Reviews, 88 (1988) 617.

[3] Z. Samec, Pure Appl. Chem., 76 (2004) 2147.

[4] D.W.M. Arrigan, Anal. Lett., 41 (2008) 3233.

[5] A. Berduque, M.D. Scanlon, C.J. Collins, D.W.M. Arrigan, Langmuir, 23 (2007) 7356.

[6] A. Trojanek, J. Langmaier, E. Samcova, Z. Samec, J. Electroanal. Chem., 603 (2007) 235.

[7] P. Vanysek, J.D. Reid, M.A. Craven, R.P. Buck, J. Electrochem. Soc., 131 (1984) 1788.

[8] P. Vanysek, Z. Sun, Bioelec. \& Bioenerg., 23 (1990) 177.

[9] J. Perrenoud-Rinuy, P.F. Brevet, H.H. Girault, Phys. Chem. Chem. Phys., 4 (2002) 4774.

[10] D.G. Georganopoulou, D.E. Williams, C.M. Pereira, F. Silva, T.J. Su, J.R. Lu, Langmuir, 19 (2003) 4977.

[11] M.Y. Vagin, E.V. Malyh, N.y.I. Larionova, A.A. Karyakin, Electrochem. Commun., 5 (2003) 329.

[12] M.Y. Vagin, S.A. Trashin, S.Z. Ozkan, G.P. Karpachova, A.A. Karyakin, J. Electroanal. Chem., 584 (2005) 110.

[13] M.Y. Vagin, S.A. Trashin, G.P. Karpachova, N.L. Klyachko, A.A. Karyakin, J.

Electroanal. Chem., 623 (2008) 68.

[14] M. Shinshi, T. Sugihara, T. Osakai, M. Goto, Langmuir, 22 (2006) 5937.

[15] G. Herzog, V. Kam, D.W.M. Arrigan, Electrochimica Acta, 53 (2008) 7204.

[16] G. Herzog, W. Moujahid, J. Strutwolf, D.W.M. Arrigan, Analyst, 134 (2009) 1608.

[17] J.E. Ellis, S.Q. Xu, X. Wang, G. Herzog, D.W.M. Arrigan, M. Thompson,

Bioelectrochemistry, (2009) doi:10.1016/j.bioelechem.2009.09.012.

[18] F. Kivlehan, Y.H. Lanyon, D.W.M. Arrigan, Langmuir, 24 (2008) 9876.

[19] M.D. Scanlon, E. Jennings, D.W.M. Arrigan, Phys. Chem. Chem. Phys., 11 (2009) 2272.

[20] A.E. Thomsen, H. Jensen, L. Jorgensen, M. van de Weert, J. Ostergaard, Colloids and

Surfaces B-Biointerfaces, 63 (2008) 243.

[21] A.I. Bartlett, S.E. Radford, Nat. Struct. Mol. Biol., 16 (2009) 582.

[22] M. Fedurco, J. Augustynski, C. Indiani, G. Smulevich, M. Antalík, M. Bánó, E. Sedlák,

M.C. Glascock, J.H. Dawson, J. Am. Chem. Soc., 127 (2005) 7638.

[23] Y. Zhu, S. Dong, Bioelec. \& Bioenerg., 41 (1996) 107.

[24] T. Ferri, A. Poscia, F. Ascoli, R. Santucci, Biochim. Biophys. Acta, 1298 (1996) 102.

[25] J. Bixler, G. Bakker, G. McLendon, J. Am. Chem. Soc., 114 (1992) 6938.

[26] P.D. Barker, A.G. Mauk, J. Am. Chem. Soc., 114 (1992) 3619.

[27] E. Paleček, V. Ostatná, Analyst, 134 (2009) 2076.

[28] X. Li, W. Zheng, L. Zhang, P. Yu, Y. Lin, L. Su, L. Mao, Anal. Chem., 81 (2009) 8557.

[29] H.G. Kristinsson, J. Agric. Food Chem., 50 (2002) 7669.

[30] T.T. Herskovits, H. Jaillet, B. Gadegbeku, J. Biol. Chem., 245 (1970) 4544. 